\title{
Spring common wheat breeding lines produced on the basis of distant hybridization: ecological strain testing in Bagan
}

\author{
B.F. Nemtsev ${ }^{1}$, A.B. Nemtsev², N.P. Goncharov ${ }^{2}$, S.V. Kurkova ${ }^{3}$ \\ ${ }^{1}$ Siberian Research Institute for Plant Industry and Breeding - Branch of the Institute of Cytology and Genetics, SB RAS, Krasnoobsk, Novosibirsk region, Russia \\ ${ }^{2}$ Institute of Cytology, RAS, St. Petersburg, Russia \\ ${ }^{3}$ North-Kulunda Department of Siberian Research Institute of Feed, Siberian Branch of the Russian Academy of Sciences
}

DOI 10.18699/ICG-PlantGen2019-07

(c) Autors, 2019

*e-mail: nembor@yandex.ru

\begin{abstract}
The article presents of studying--under the conditions of the agriculturally risky Kulunda steppe-the ecological homeostasis of spring common wheat breeding lines created using remote hybridization. The studies were carried out at the breeding and seed sector of grain and feed crops of the Siberian Research Institute of Feed North-Kulunda Department. One of the important indicators characterizing the resistance of plants to adverse environmental factors is homeostasis, a universal property in the system of the relationship between the genotype and the environment. Homeostasis is the ability of the genotype to minimize the effects of adverse external conditions. Statistical processing was performed using a package of Snedecor applications. We carried out the analysis of the homeostasis of the selection lines according to the algorithms developed by S.P. Martynov, the yield variance analysis of multiyear experience according to Tomilov, and multidimensional ranking of varieties on the main breeding traits, which was designed by I.A. Uzhakov. A breeding line (1459-E-06) of spring common wheat with high responsiveness to the environmental conditions and stable high yield was selected. This line was made by crossing spelt with durum wheat and further backcrossing with common wheat. This line is advisable for use as a source of high productivity of plants in the selection process, to obtain new genotypes with high adaptive properties and is recommended for transfer to the state strain testing.
\end{abstract}

Key words: spring wheat; interspecific hybridization; homeostasis; agronomic traits.

\section{Introduction}

Interspecific hybridization is currently one of the most effective breeding methods. The hybridization of common wheat with the hexaploid species Triticum compactum Host and T. sphaerococcum Perc. is easy as these species are genetically compatible. The use of wheat species in practical breeding is usually associated with the production of easily threshable forms.

Crossing of common wheat with T. sphaerococcum Perc. is promising, as it results in hybrids with high grain quality and early maturity. In addition to these properties, such hybridization allows plants with a solid straw, drought resistance and frost resistance to be obtained (Dorofeev, 1987).

When crossing spelt with common wheat, new varieties are resistant to diseases. In the world of wheat breeding, spelt played an important role as the initial form for interspecific crosses. N.I. Vavilov in 1911-1913 found hybrids with resistance to powdery mildew and brown rust. He considered promising the crossing of spelt with common and durum wheat cultivars (Vavilov, 1935). When inheriting signs of spelt, it dominates if it is taken as a mother plant.

\section{Materials and methods}

Modern breeding is based primarily on the use of the existing diversity of germplasm cultivated plants. And only carrying out distant hybridization with wild relatives allows makes it possible to increase it to an extent as well as to transfer it from some systematic units to other economically valuable traits or properties (Goncharov N.P., Goncharov P.L., 2018).
Through the use of distant hybridization, the breeder is looking for opportunities to expand the biodiversity of existing new economic plant species. In the Sector of Wheat Genetics, N.P. Goncharov produced common wheat hybrids with T. compactum, T. sphaerococcum, T. dicoccum, T. durum, Aegilops squarrosa (Table 1).

In these hybrid combinations, individual selection was carried out on the basis of signs of the main spike (length, number of spikelets, number of grains, mass of grain), with using of a selection criterion according Nemtsev (1989). The lines selected were tested according to the basic breeding scheme. Field experiments, observations and processing of the results of the experiment were carried out according to Armor (1985), and analyes and accounting according to VIR methods (Fedin, 1985). Statistical processing was performed using the Snedecor application package (Yuzhakov, Sorokin, 2000).

\section{Results and discussion}

As a result of the long selection of breeding lines, four lines have been allocated for environmental testing at the North Kulunda Department of Siberian Research Institute of Feed, During selection, it was taken into account that the lines should be adapted to unfavorable growing conditions. Attention was paid to the survival of plants. Only those lines that had a strong stem were selected, because of the humid continental climate. Soils are poor chernozems often with a loamy composition; salt licks; marsh soils. The weather conditions of the growing seasons of 2016 and 2017 were dry in Bagan, the amount of precipitation did not reach the average multi-year norm; in 
Table 1

The origin of the lines

\begin{tabular}{|c|c|c|c|c|}
\hline Breeding line & Origin & Generation (Progeny selection) & Selection type & Year \\
\hline 1459-E-06 & $\begin{array}{l}((\text { BS1E T. dicoccum x \# } 668 \text { T. durum }) \times \text { Novosibirsk 29) } \times \\
\text { Novosibirsk } 29\end{array}$ & $\mathrm{~F} 18(\mathrm{~F} 6)$ & individual & 2006 \\
\hline $1486-E-10$ & $\begin{array}{l}\text { [(Novosibirsk } 20 \times(\mathrm{k}-23790 \text { T. sphaerococcum India } \times \\
\text { Cl3090 T. compactum USA })) \times \text { Novosibirsk 29] } \times \\
\text { Novosibirsk } 29\end{array}$ & $\mathrm{~F} 16(\mathrm{~F} 6)$ & individual & 2008 \\
\hline 1488-E-09 & $\begin{array}{l}\text { (Bezostaya } 1 \times \text { Siberian 62) } \times \text { KU 221-24 (Vernal } \\
\text { T. dicoccum } \times \text { KU2074 Aegilops squarrosa) }) \times \\
(\text { Bezostaya } 1 \times \text { Siberian 62)] }\end{array}$ & F16(F7) & individual & 2009 \\
\hline 1436-E-03 & Novosibirsk $20 \times$ Astella (Czech winter variety) & $\mathrm{F} 18(\mathrm{~F} 3)$ & individual & 2003 \\
\hline
\end{tabular}

Table 2

Structure of the harvest (2016-2018)

\begin{tabular}{|c|c|c|c|c|c|c|c|c|c|c|c|c|}
\hline 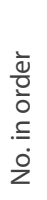 & 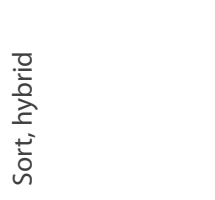 & 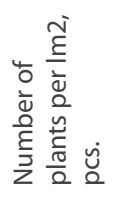 & 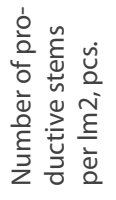 & 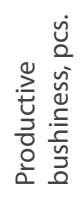 & 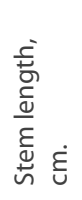 & 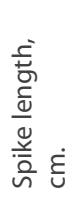 & 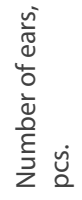 & 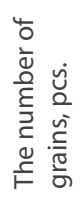 & 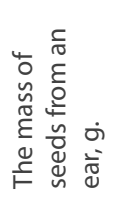 & 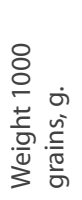 & 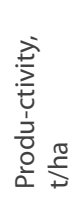 & 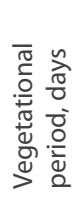 \\
\hline 1 & Omskaya 36 (st) & 191,5 & 250,8 & 1,3 & 73,7 & 6,5 & 9,5 & 24,1 & 0,90 & 35,0 & 2,33 & 75 \\
\hline 2 & 1459-E-06 & 264,7 & 338,5 & 1,3 & 67,1 & 6,0 & 9,0 & 23,5 & 0,78 & 32,7 & 2,64 & 76 \\
\hline 3 & 1486-E-10 & 277,6 & 314,0 & 1,2 & 64,4 & 5,1 & 9,0 & 20,6 & 0,60 & 29,0 & 1,97 & 75 \\
\hline 4 & 1488-E-09 & 260,8 & 330,0 & 1,3 & 63,2 & 4,9 & 9,0 & 22,3 & 0,60 & 27,2 & 1,97 & 75 \\
\hline \multirow[t]{2}{*}{5} & 1436-E-03 & 185,7 & 263,4 & 1,5 & 68,7 & 6,4 & 10,3 & 22,8 & 0,72 & 31,5 & 2,04 & 75 \\
\hline & NSR05 & 42,9 & 60,8 & 0,15 & 4,04 & 0,72 & 0,59 & 0,91 & 0,15 & 2,5 & 0,13 & 1,0 \\
\hline
\end{tabular}

Bakery evaluation showed that line 1459-E-06 is the best and belongs to the group of strong wheat (Table 3 ).

Table 3

Grain quality (2016-2018)

\begin{tabular}{|c|c|c|c|c|c|c|c|c|c|c|}
\hline \multirow[b]{2}{*}{$\begin{array}{l}\text { No. } \\
\text { in order }\end{array}$} & \multirow[b]{2}{*}{$\begin{array}{l}\text { Sort, } \\
\text { hybrid }\end{array}$} & \multirow[b]{2}{*}{$\begin{array}{l}\text { Natures, } \\
\text { g/l }\end{array}$} & \multirow[b]{2}{*}{$\begin{array}{l}\text { Vitreous- } \\
\text { ness (\%) }\end{array}$} & \multirow[b]{2}{*}{$\begin{array}{l}\text { Gluten } \\
\text { wine }\end{array}$} & \multirow[b]{2}{*}{$\begin{array}{l}\text { IDK-1, } \\
\text { units ap- } \\
\text { pliance }\end{array}$} & \multicolumn{3}{|c|}{ Aveogramma } & \multirow[b]{2}{*}{$\begin{array}{l}\text { Volume } \\
\text { of bread } \\
\mathrm{cm} 3 / 100 \mathrm{~g}\end{array}$} & \multirow[b]{2}{*}{$\begin{array}{l}\text { Total bak- } \\
\text { ery grade, } \\
\text { score }\end{array}$} \\
\hline & & & & & & $\begin{array}{l}\text { Flour } \\
\text { strength, } \\
\text { e.a. }\end{array}$ & $\begin{array}{l}\text { Dough } \\
\text { elasticity, } \\
\mathrm{mm}\end{array}$ & $\mathrm{P} / \mathrm{L}$ & & \\
\hline 1 & Omskaya 36 (st) & 759 & 50 & 28,2 & 60 & 511 & 103 & 1,28 & 760 & 4,1 \\
\hline 2 & 1459-E-06 & 762 & 50 & 29,3 & 62 & 589 & 107 & 1,32 & 760 & 4,3 \\
\hline 3 & 1486-E-10 & 702 & 50 & 36,6 & 74 & 277 & 46 & 0,22 & 660 & 3,8 \\
\hline 4 & 1488-E-09 & 718 & 50 & 29,2 & 62 & 400 & 65 & 0,26 & 720 & 4,3 \\
\hline \multirow[t]{4}{*}{5} & 1436-E-03 & 706 & 56 & 30,5 & 72 & 299 & 57 & 0,32 & 620 & 4,0 \\
\hline & The average & 729,4 & 51,2 & 30,8 & 66,0 & 415,2 & 75,6 & 0,680 & 704,0 & 4,10 \\
\hline & $\begin{array}{l}\text { Standart } \\
\text { deviation }\end{array}$ & 25,95 & 2,40 & 3,01 & 5,80 & 120,18 & 24,78 & 0,507 & 55,71 & 0,19 \\
\hline & Medium error & 11,61 & 1,07 & 1,35 & 2,59 & 53,75 & 11,08 & 0,227 & 24,92 & 0,08 \\
\hline
\end{tabular}


Table 4

Ranking of objects according a set of signs

\begin{tabular}{lllll}
\hline Place of the object & Sort, hybrid & Sum of ranks & Sum of weighted ranks & Euclidean distance \\
\hline 1 & $1459-\mathrm{E}-06$ & 79,0 & 79,0 & 1311,7 \\
2 & Omskaya 36 (st) & 69,5 & 64,5 & 1242,9 \\
3 & $1436-\mathrm{E}-03$ & 60,5 & 55,5 & 1049,1 \\
4 & $1488-\mathrm{E}-09$ & 48,0 & 43,0 & 1180,4 \\
5 & $1486-\mathrm{E}-10$ & 43,0 & 38,0 & 1097,0 \\
\hline
\end{tabular}

Table 5

Evaluation of homeostasis varieties

\begin{tabular}{|c|c|c|c|c|}
\hline No. in order & Sort, hybrid & Productivity, t/ha & Homeostatism & \\
\hline 1 & 1459-E-06 & 2,66 & 4,58 & above the average \\
\hline 2 & Omskaya 36 (st) & 2,33 & 1,45 & above the average \\
\hline 3 & 1436-E-03 & 2,04 & $-1,45$ & below the average \\
\hline 4 & $1486-E-10$ & 1,97 & $-2,17$ & below the average \\
\hline 5 & 1488-E-09 & 1,96 & $-2,41$ & below the average \\
\hline Medium index & & 2,189 & & \\
\hline NSR05 & & 0,079 & & \\
\hline
\end{tabular}

2018, $204.4 \%$ fell out during the growing season, and the average daily air temperature was $1.5^{\circ} \mathrm{C}$ below the multiyear average.

Univariate analysis of variance of plants showed that line 1459-E-06 was significantly superior to the standard: it had 73.2 more plants per square meter, 87.7 more productive stems per square meter, its yield was increased by $0.31 \mathrm{t} / \mathrm{ha}$, and the stems were $6.6 \mathrm{~cm}$ shorter. There were no significant differences in the rest of the signs (Table 2).Based on the above data, we carried out a multidimensional ranking of the varieties according to the main breeding characteristics developed by A.I. Yuzhakov. The program is designed for a multidimensional ranking of study objects (varieties of crops, animals, soil samples, etc.) according a set of features, the values of which, increasing from minimum to maximum, reflect their economic (or other) value. In fact, this is a method of an automatic classification of objects into three groups, according to the principle of increasing the distance of objects from the origin of coordinates, expressed by a generalized rank.

Since signs can have different degrees of utility, it is possible to specify a certain system of weights for each attribute, in the form of numbers from -10.0 to 10.0 (a negative weight value is for signs reflecting negative, undesirable properties of objects); if you do not specify the weight, the program assumes that all signs have an equal degree of utility (1.0). For the same data set, several rankings can be made by varying the weights system. According to the results of a comprehensive assessment of traits with weights $(+1.0)$ and only for the growing season (-1.0), line 1459-E-06 comes first (Table 4).

An important place in the selection of ecologically plastic varieties is occupied by the theory of homeostasis as the ability of plants to maintain internal balance and unleash the genetically determined potential of the variety at the phenotype level when conditions become abnormal (Yusufov, 1983). The state of homeostasis can be used as the main criterion for assessing the genotype. The measure of homeostasis of a variety is its ability to keep yield reductions to a minimum when conditions of cultivation deteriorate. The above is of great importance for obtaining not only maximum, but also stable yields in a wide range of growing conditions. Stable grain yield indicates high homeostasis. In contrast, large variability is indicative of a low homeostasis of the genotype with the same limiting environmental factors (Sapega, 1988). It has been established that high homeostatic genotypes in agrocenoses give less variation in plant productivity and slightly reduce yield with thick sowing or a combination of adverse factors with thickening (Hangildin, Litvinenko, 1981). Homeostasis is associated with tolerance to adverse environmental factors (Allard, Bradshaw, 1964).Analysis of the homeostasis of breeding lines according to the algorithm developed by S. S. Martynov was carried out. This program was designed to analyze the homeostasis of a certain set of varieties in an experiment performed in one of two ways: in growing conditions at several geographically dispersed points, or in different modes specially created in artificial growth chambers; for several years at one point, as in the present research.

\section{Conclusions}

Thus, the use of the existing set of techniques to identify potential productivity of agricultural crops makes it possible to establish the reliability of the observed differences and obtain the necessary information for the selection of valuable start- 
ing material in the selection for adaptability. A selection line (1459-E-06) of spring soft wheat with high responsiveness to environmental conditions and stable yield was selected. This line was produced by crossing spelt with durum wheat and further backcrossing with common wheat. The line gave an increase in yield due to better survival of plants. This line is advisable to use as a source of high productivity of plants in the breeding process, to obtain new genotypes with high adaptive properties and is recommended for transfer to state trials.

\section{References}

Allard R.W., Bradshaw A.D. Implication of genotype environmental interaction in applied plant breeding. Crop Sci. 1964;4:503-508.

Armor B.A. Methods of field experience (with the basics of statistical processing of research results). Moscow, 1985.

Fedin M.A. Methods of state variety testing of agricultural crops. Publisher: USSR Ministry of Agriculture. 1985.

Goncharov N.P., Goncharov P.L. Methodical bases of plant breeding. $3^{\text {nd }}$ ed. Novosibirsk: Acad. Publ. house "Geo", 2018
Hangildin V.V., Litvinenko N.A. Homeostaticity and adaptability of winter wheat varieties. Scientific Technical Bul. 1981;1:8-14.

Nemtsev B.F. Refinement of selection parameters by quantitative characteristics. Sat scientific tr. In: VASKhNIL. detachment SibNIIRS. RPO with the Academy of Agricultural Sciences, 1989;74-80.

Sapega V.A. Productivity and homeostasis of zoned varieties of spring wheat. Bul Agricultural Sci Kazakhstan. 1988;10:24-28.

Vavilov N.I. Scientific bases of wheat breeding. Moscow; Leningrad, 1935.

Dorofeev V.F. (Ed.). Wheat of the world; 2nd ed. Leningrad, 1987.

Yusufov A.G. Homeostasis and its significance in the ontogeny of plants. Agricultural Biol. 1983;1:25-35.

Yuzhakov A.I., Sorokin O.D. Software package applied "Snedecor V4" for processing data obtained in biological experiments. Information technologies, Information measuring systems and devices in research of agricultural processes, Materials of the regional scientificpractical conference. Novosibirsk, 2000.

Acknowledgements. The work is supported by the RSF grant 16-16-10021P.

Conflict of interest. The authors declare no conflict of interest. 